\title{
Beware of High Conflict Personality Disorders: Implications for Mediation
}

\author{
Joan Jutta Lachkar \\ Affiliate Member, New Center of Psychoanalysis, West Los Angeles, CA 91316, USA.
}

How to cite this paper: Joan Jutta Lachkar. (2022) Beware of High Conflict Personality Disorders: Implications for Mediation. International Journal of Clinical and Experimental Medicine Research, 6(1), 81-89.

DOI: 10.26855/ijcemr.2022.01.014

Received: November 20, 2021

Accepted: December 18, 2021

Published: January 19, 2022

*Corresponding author: Joan Jutta Lachkar, Affiliate Member, New Center of Psychoanalysis, West Los Angeles, CA 91316, USA.

Email: jlachkar@aol.com

\begin{abstract}
This work is an expansion of my groundbreaking book, The Narcissistic/Borderline Couple where I describe what happens when a narcissist and a borderline join together in a marital bond and do what I refer to as "the dance" [1]. Aside from this work, it has applicability to all kinds of couples including couples going through divorce. Many practitioners treat patients going through divorce experiencing difficulties with individuals with high personality disorders in legal mediation. This article applies mainly to narcissistic, borderline, and obsessive-compulsive personality disorders and how their primitive defenses get in the way of reaching conflict resolution. Instead, they will fight to the bitter end to get their demands met even to the extent of destruction to self and others (spouse, children, family, career, reputation) until they achieve their final goal-revenge. Therapists and legal officials are continually perplexed as to why people continue to battle.
\end{abstract}

\section{Keywords}

Narcissist, borderline, obsessive compulsive, histrionic, The V-spot, primitive defenses, mediation, marital therapy, psychodynamics, primitive defenses and cross-culture

Happy families are alike; every unhappy family is unhappy in its own way.

* "Suddenly my head begins to spin. I feel dizzy and confused. My head keeps going round and round. In front of me sits a married couple; they go on and on in circles, going nowhere. A feeling of despair overwhelms me as I think to myself, "This couple needs to be in therapy." And then realize l am the therapist!"

-Leo Tolstoy, Anna Karenina

This article brings "love relations" into the court system, mainly describing how couples with high-conflict disorders manipulate the court system and the impact it has on families and children [2]. This chapter details how court officials and mediators struggle to deal with couples, once in love and now bitter enemies who try to manipulate and abuse the system. It illustrates the stresses and strains put on the court when met with the excessive demands of certain personality types, e.g., the narcissists grandiose and entitlement fantasies as it distinguishes the differences between couples' therapy and mediation. Although I am not a divorce lawyer, I have consulted with many experts in the field of family law. Many practitioners treat patients who are experiencing difficulties with partners with high conflict personality disorders (HCPD) in legal mediation and court custody. A person will fight

\footnotetext{
* Portions of this chapter were in papers presented at the Winter Conference of the Association of Family and Conciliation Courts (AFCC) on December 13, 1985, in San Diego, CA and at the AFCC 53rd Annual Conference, Modern Families: New Challenges, New Solutions, June 1-4, 2016, Sheraton Seattle Hotel, Seattle, WA. The paper was originally published in Conciliation Court Review, June 1986, pp. 31-43.
} 
to the bitter end, even to the extent of sacrificing self and others (spouse, children, family, career, reputation) until they achieve their final goal. Therapists and legal officials are continually perplexed as to why people continue their never-ending battle without ever reaching conflict resolution. Reference is made to the male gender instead of "she/she" however the reader is free to reverse the roles.

We were just about ready to reach a resolution with my hoarder OCPD husband. I discarded everything in our house got rid of all the junk he accumulated. I was really getting excited until I saw that he went into the trash and brought everything back that I had thrown away!

Nothing is as highly emotionally charged as couples going through divorce and custody battles. When couples divorce, little do they know of the horrors that await them. Emotions are high. Lies, false accusations of child abuse/molestation, forgery, purposeful building of huge legal fees, unwarranted restraining orders, out-of-control behavior in front of children are some of the behaviors that these couples exhibit when legal mediation begins. As children many take on the role as "little adults" "mini mediators," act as intermediaries in their parent's marital disputes. Often these children are forced by circumstances to grow up much too early because they feel responsible for their parent's divorce. These issues stir up highly charged reactions or what I refer to as "V-spots" triggering many unresolved old archaic injuries [3-6].

In recent years, an increasing number of mediators, lawyers, and court officials have consulted extensively with clinicians and other mental health professionals in dealing with couples with personality disorders-also known as "impossible couples." These are individuals who are dominated by primitive defenses and exhibit highly volatile behaviors. In many of my other publications, I refer to the highly charged emotional reactions marital conflict elicits as "V-spots," through which each partner stirs up some highly charged unresolved archaic injury in the other [3-6]. Does each of each of these disorders have their own unique spot? I believe they do!

\section{My wife is insatiable, whatever is offered is never enough!}

Until recently the narcissistic personality has been my major focus and has been in the spotlight with an enormous amount of attention. People were using the term as a household word. After writing Courts Beware of the Borderline [7]. I started to realize there are many other personality types that enter onto the court arena. We now bring forth a new character one which has recently gotten a lot of attention, the obsessive-compulsive personality.

Many practitioners and those in the court system are experiencing difficulties with high-conflict people in legal disputes. The narcissist for example will fight the end to prove their specialness and entitlement fantasies. Those with borderline personality disorder also will not fight but get into modes of revenge and retaliation against the spouse who is felt to betray or abandon them. Even to the extent of sacrifice and destruction to self and others (spouse, children, family, career, reputation) until they achieve their final goal-revenge retaliation to the spouse who is felt to betray or abandon them. For the borderline revenge and retaliation becomes a more pervasive force than life itself! The obsessive on the other will enact is withholding anal retentiveness by making demands that will forever stall the resolution process to endless time in court. As one mediator expressed out of frustration, "There is no perfect document that will satisfy this guy!” On the surface they appear normal; many are intelligent, high-functioning professionals, and present a very attractive personality yet they can dupe even the most well-seasoned therapist. But lurking in the shadows is an uncontrollable impulse to withhold, sabotage does not comply or take heed to advice of others.

Therapists and legal officials are continually perplexed as to why these individuals cannot make peace or take in good advice from others. Why do they bond with pain? According to [23], individuals with HCPD stay forever and relentlessly attached to familiar and their internal "bad objects". On the surface, couple issues seemingly revolve around children, sex, money, commitment, work, outside intrusions (ex-spouses, in-laws, friends, sports, pets, hobbies). But the underlying issues are more about control, domination, envy, jealousy, shame, guilt, submission, victimization, and oedipal rivals.

\section{The V-SPOT (The VULNERABLE SPOT)}

My concept of the V-spot [3] has applicability in court proceedings dealing with divorce that involve those with HFPD who share many attributes of what I refer to as "household terrorists" or "court terrorists". This is a term I restored as the epicenter of one's most vulnerable area of emotional sensitivity that unwittingly gets aroused when one hits a sensitive cord, When the V-spot is ignited, the first thing that goes is the ego: judgment, memory, perception, reality testing, impulse control, tolerance and ego identity. It is a very slippery term. Even the most 
well-seasoned mental health professionals lose sight of how early trauma impacts ego function and contaminates the power of reason and judgment.

At the least provocation it blows (pushing buttons) as things get shaken everything shifts, memory, perception, and most importantly reality and judgment, also known as the archaic injury. The V-spot is inextricably linked to the ego apparatus and its capacity to think and function). The dysfunctionality of the ego helps us understand why people say and do absurd things and account for patient's distortions, delusions, and misperceptions. What makes an anorexic think he/she is fat? What makes a shopaholic think they can afford to buy the things they can't? What makes a person with no talent or a "wannabe" think that they will become rich and famous? What makes narcissists think they are entitled to things they're not or the borderline that acting the role of the victim will bring love or self-esteem. What makes an obsessive-compulsive think that cleaning will up will become the replacement for the desire for intimacy.

Does each of these disorders have their own specific area of vulnerability or V-Spot. Yes, I believe they do. The narcissist gets triggered with their sense of specialness or entitlement gets threatened. And the borderline gets triggered when sense of betrayal or abandonment get stirred up. When injured, the narcissist will withdraw. As opposed to the borderline will attack or go into borderline rage (ink we are all familiar with "borderline rage!” I will now move on to defining a narcissistic/S/borderline relationship a very common couple in clinical practice but in mediation and custody battles as well),

\section{Defining Narcissist/Borderline Relationship}

This is a beleaguered type of relation between two developmentally arrested people consciously or unconsciously stir up highly charged feelings that fulfill many early unresolved conflicts in the other. The revelation is that each partner needs the other to play out his/her own personal relational drama. These are remnants of old hurts, archaic injuries embedded age old sentiments that they bring into their current relationship (baggage). Together these oppositional types enter into a psychological drama as each coerce each other into playing out certain roles (the nag, the controlling mother, abusive father). In the dance, how each one projects a negative part into the other and how the other identifies or over-identifies with that which is being projected. You can imagine how this arouses feelings of unworthiness and shame in the borderline one who already deserving already has a thwarted sense self and does not feel deserving.

A narcissistic husband projects a feeling into his borderline wife that she is worthless and not entitled to anything and should not need or want anything. He complains, "All you do is nag, nag, nag." Not knowing how to legitimately express her real needs, the borderline wife continues to nag/demand. The more she nags, the more he withdraws, the more he withdraws she attacks. As she attacks, she hooks into his harsh punitive internalized superego (guilt). He ends up feeling guilty and she shamed. Thus, it becomes a dance between guilt and shame.

\section{The Narcissist: A Sketch of The Narcissist, The Entitlement Lover}

The narcissist is the entitlement lover, the special child of God (also known as "His Majesty the Narcissist." You know when you are around one because all they talk about is themselves. They are dominated by a grandiose and exaggerated sense of self, believe the world owes them something and feel they are superior to others. They have excessive entitlement fantasies. In court custody cases are most difficult. They are the ones who feel entitled, want all the visitation, the money, all the furniture). They value such things as success, fame, physical beauty, wealth, material possessions, and power. The narcissist cannot tolerate having dependency needs and unwittingly project their needy selves into the borderline, According to Kernberg [27] narcissists cannot tolerate the kinds of dependency needs of an intimate relationship, they unwittingly project their dependent and "needy" selves onto the other. (Often a borderline who is a perfect target for the narcissist's negative projections). In treatment narcissists are the ones who will quickly flee when injured, not appreciated, when confronted, not properly mirrored, or when their excessive demands are not met. They are always asking for special favors, changing appointment times, coming in only when it suitable for them. The narcissist cannot allow themselves the kind of dependency an intimate partner yearns!

It is you that is the needy one! Me, I am perfect as mother wants me to be! I don't need you and I don't need this treatment! 


\section{The Borderline Sketch of the Borderline The Victim the Abandoned One}

The key to handling borderlines when mediation with their partners bogs down is to understand the nuances and motivation of the borderline persona. Borderlines are often "as-if" personalities and have an exquisite false self [14]. They can dupe the most seasoned therapists, let alone court officials, with the façade of being the poor victims, the betrayed and abandoned ones. To defend against shame, they are determined to win and prove their self-righteousness at any cost. They may appear normal, genuinely concerned about the welfare of the family, are intelligent and often charming. But behind this façade they scheme to coerce their partner into the "bad parent" role (in psychoanalytic terms, this is known as splitting and projective identification).

\section{The Obsessive-Compulsive: A Sketch of the Obsessive-Compulsive To Clean is to Eradicate Needs and Feelings}

The obsessive-compulsive personality disorder (OCPD) differs from the obsessive-compulsive disorder (OCD) in that the OCD is an anxiety disorder [8] in progress. The main difference is that the OCD have thoughts they know are intrusive and do not want as compared to the OCPD who believe their thoughts and behaviors are justified e.g., an anorexic with food — what to eat, when to eat, looks in the mirror and think they are "fat!" Devoid of feelings, the OCD revert to compulsive cleaning, washing, checking and rechecking and other repetitive acts. In OCPD, there is a pervasive preoccupation with orderliness, perfectionism and ritualistic behaviors. Patients who suffer from this disorder have a great deal of shame which leads them often to withdraw and isolate themselves. Such obsessions may include concerns about germs and that they will contaminate themselves and others. To guard against shame of having emotions and feelings the OCD resort to compulsive cleaning, handwashing, rituals, praying, counting, checking, rechecking and other repetitive behaviors and collecting and hoarding of objects. Ironically, they can never be perfect enough to satisfy themselves. On a more positive note, because of their obsession they are often successful in business and other professions.

Let us take a moment to note the differences between mediation and couple therapy.

\section{Difference Between Mediation and Couple Therapy}

Mediation has become a common and alternative attempt to resolve domestic (divorce, child custody, and visitation) disputes in lieu of court involvement. Some court systems require mediation as mandatory in an attempt to help partners come to terms with disagreements and find ways to reach conflict resolution without causing either emotional or physical harm to themselves or their partners. Mediation is a task-oriented method to alleviate disputes through negotiation and reach conflict resolution. This means that decisions are not based on how one "feels" but are more about the "needs" of the family. Past experiences such as early childhood trauma, attachment disorders, family conflicts do not matter. Mediation is guided by a group of trained lawyers and mediators that are by law involved in the decision-making process. Reaching resolution is not based on a person's past, personality defects, or traumatic experience, but more about who is most qualified to care for the child if equal time sharing for custody agreement is not met. In fact, it does its best to break through the defenses to allow the raw self or true self to emerge [7].

Couple therapy provides a more in-depth approach to working through the couple conflicts and disagreements. It considers such matters as family conflict, childhood trauma, and attachment disorders. Couple therapy is an experience that occurs among three persons. I coined the term "couple transference" [3-6] to show how the couple projects onto the therapist. The deeply emotional experience of intense communication and feelings that therapy entails begins with acknowledging the profound challenges of a primitive relationship and matures into the awareness of healthy dependency needs and mutual respect. The couple presents its own dramatic narrative, and with each session the curtain opens on the opportunity to create a new experience. Unlike mediation, couple therapy does not have a group of laws to back it up. You can't say, for instance, "Well, there is a law that says you must take your wife out for Valentine's Day and buy her flowers!" The experience is more subjective, and the needs of the couple gradually unfold as therapy continues. Couple therapy can be long or short term, whereas mediation is designed to be brief

A borderline patient disclosed that she loves the court system. She feels that for her whole life people have been against her. Now she has a family court that listens to her, defends her, and treats her like a human being. If my OCPD husband doesn't listen to me, the judge will! 


\title{
Personality Disorders and Family Court Litigation
}

People with personality disorders usually experience chronic internal chaos and distress (fear of abandonment, as well as unwarranted issues around betrayal, and trust) and exhibit self-sabotaging behavior. They are dominated by such issues as rage, envy, lack of impulse control, unleased aggression, an excessive need to control/dominate, and unresolved oedipal issues. These predominant conflicts place extreme pressure on marriages and children and can lead to the most contentious divorces.

Most commonly, they are characterized by their bullying, tormenting, aggressive, controlling, sadistic, and domineering acts. These acts can fluctuate from intense rage and bullying to victimization. Furthermore, those with OCPD are the ones who tie up the court systems with endless complaints and declarations—not for the purpose of reaching resolution but to destroy the person who they perceive has betrayed them. Because of childhood abuse, trauma, or neglectful bonding experiences, they grow up perceiving the world as a dangerous and frightening place. Unfortunately, they find attorneys who collude with their pathology. The OCPD also crosses over with the antisocial, who has little regard for rules and authority, lacks empathy and conscience, and has no regard for the impact their destructive behavior has on others.

Also common is the narcissist personality disorder, those who suffer from excessive entitlement fantasies and have a belief system that they are superior to others. One thing they all share is the lack of rational thought, logic, and reasoning. Because of their severe defense mechanisms, they exhibit what I refer to as ego dysfunctionality. With their altered sense of perception, they view the world through distorted lenses; in some cases, they are delusional, which constitutes their rationale for lies, deception, and false accusations. Collectively they lack the filter between id and superego functioning that tells right from wrong. For example, it is wrong to falsely accuse one's spouse of child abuse in the hopes he will lose his job, or to go around bad-mouthing one's spouse to children or others.

Within the complexity of the relationships of those with personality disorders, one can readily see how court systems can become perplexed and preoccupied with trying to understand how to deal with the various types of oppositional couples. Even when apart, separated, or divorced, such couples maintain a tie or a bond, albeit a parasitic and abusive/destructive bond that never allows the partners to reach a final resolution. The most striking feature of this unconscious parasitic or traumatic bonding is a clinging kind of dependency that differs dramatically from a healthy dependency.

In many of my publications, I have referred to these kinds of painful attachments, most specifically for the borderline, whose desire to remain forever bonded or connected is a more pervasive force than life itself [9]. For the borderline, it is preferable to stir up highly charged feelings, to repeat the same trauma again and again. "Better to feel or induce pain rather than face an empty, impoverished internal world”. In unspoken language, the borderline communicates his/her disappointment with an archaic, empty mother, projecting onto the narcissistic partner the fantasized mother capable of making up for all the early losses. Through blaming and attacking mechanisms, they express disappointment that the other has failed to provide a "holding environment" [14] and to be the all-encompassing available mother preoccupied with her "child/husband". When this fantasized holding environment is threatened (as in divorce), an intense fear ensues, along with the desire to "get back", to retaliate. Revenge and getting even then becomes the pervasive force governing behavior. This explains why court officials are puzzled and fail to understand why children are often placed in the middle of arguments, are deprived, made to be "go-betweens", and forced to become little adults and play the role of mediators, "saviors/messiahs" [15].

It has been over twenty years and my OCD husband to this day refuses to pay alimony and child support. And now he doesn't help pay for our daughter's college education because he's a hoarder, stubborn, and very withholding.

\section{Where Do Psychology and Mediation Meet?}

\begin{abstract}
As mediators, we really don't care so much about your feelings and the importance of your attachment to your possessions and objects. Our job to follow the law and recognize the law and legal rights regarding community property.
\end{abstract}

More and more mediators stuck in the quagmire of these beleaguered couples and their antagonistic types of relationships are becoming increasingly aware of the importance of understanding various personality types. For example, someone with a narcissistic personality will be more concerned with possessions, feel entitled to have it all 
(the custody, the money, the house, the furniture, the pets) compared to the borderline, who could care less about possessions but is all about revenge and spending the rest of their life retaliating, getting back at the spouse or "mommy" whom they perceive has abandoned or betrayed them.

Family court has an advantage over therapists in that there is a powerful authority figure, the judge who calls the shots regardless of the mental state of those involved? The focus is not so much about how one feels but more about law and what is best for the family. The courts do, however, have the authority to order counseling for parents, especially if there is a potential threat or danger to the best interests of the child.

\section{Cross-Cultural Couples}

Today our consultation and courtrooms are beginning to look like a mini-United Nations filled with individuals and couples with various backgrounds-multicultural couples, cross-cultural couples, interracial couples, inter-ethnic couples, same-sex marriages, blended family marriages, and stepfamily marriages. Many people do not realize that when they intermarry they are tying the knot with an entire culture and with them also bring their nationalistic flags. Marry me marry me, marry my family which includes my religion, ideology, childrearing practices, gender, and political heritage. As a psychohistorian, studying cultures primarily Asia and the Middle East led me to my interest in cross-cultural couples. Using psychoanalytic tools and concepts has provided me the tools to examine cultures, and groups by exploring their religion, ideologies, child rearing practice and the leaders they identify with. Living is a multicultural world. I find the study of their varying dynamics a useful tool in finding discrepancies not only in our culture but even within one's own culture.

In my culture there is no such thing as community property we share everything!

\section{Do Cultures Have a Cultural V-Spot?}

Do Cultures have a cultural V-spot? Do they blow at the slightest provocation? Does one country say to another "You heart my feelings there I will not buy Turkish coffee from you! Yes, I believe they do! In noting the parallels between marital and political conflict Is that I do believe like couples, cultures also have V-spots archaic traumatic injuries bonded through was, losses or a lifetime of governmental violations keeping them forever embroiled in endless feuds. What follows are some psychodynamics varying cultures for therapists and court officials to be aware of [16].

\section{Psychodynamics and Cross-Cultural Psychodynamics}

Just as there is dance between the cultures but there is also a dance between their psychodynamics

What shame dependency, honor concept of self takes on an entirely different shape.

- Dependency (Amae)

- Harmony (wa)

- Shame/honor

- Saving Face

- Compliance vs. Confrontation

- True and False Self (honne vs. tatamae)

- Hierarchy

- Individual Self vs. Group Self

- Peace, opportunity

- Truth, lies, promises

- Magical thinking (I wish it therefore shall be)

\section{Dependency (Amae)}

I don't have to ask for what I need you will just know.

A western psychoanalyst will encourage the patient to express his/her needs as directly and openly as possible, but a Japanese patient will remain silent, waiting for the analyst to offer what he or she needs (amae). What dependency in our culture takes on a completely different mean in another? A Western psychoanalyst will encourage the 
patient to express his/her needs as directly and openly as possible, but a Japanese patient will remain silent, waiting for one to offer what he or she needs.

\section{Envy and Jealousy}

In my culture women are subservient to men!

Because she is desired she must be destroyed!

Envy is destructive where one wants to destroy the enviable object that needed, e.g., making the wife feel as though she does not exist (shame/humiliation). Jealousy is where one admires and wants what the other has but is not destructive. Mediators and therapists must face the unpleasant task of addressing the devaluation of women in certain cultures [16].

\section{Shame and Guilt}

Of course, this process is taking longer because you have sat here passively did not express your needs are and now you feel taken advantage of!

In the West, people are expected to feel guilty about certain acts. In Japan, shame is a major component of the culture, as many scholars affirm. Shame constitutes a major sanction, whereby people are humiliated and made fun of [16]. The most common threat that a Japanese mother uses to discourage behavior of which she disapproves in her children is to say Warawareru wa yo! (People will laugh at you!). In Japan, people are encouraged to hide their feelings in order to save face. For example, in Islam, it is common for one to be isolated from the group or severely punished "honor killings."

\section{Individual Self vs. Group Self}

Of course, this process took longer because we had to wait approval from your entire family!

In many societies, particularly those in Asian and Middle Eastern countries, the individual self is virtually non-existent. Where American culture emphasizes uniqueness and self-expression, Asian societies stress the group self. If the individual defies the group he/she can be subject to humiliation, ridicule, and may even become an outcast.

\section{The Cross-Cultural Hook}

But even in your own culture this is not acceptable!

The cross-cultural hook is a means to find pathology within each partner's own culture by pinpointing cultural contradictions and hypocrisy. For example, a Japanese wife finds solace in nursing her baby (sleeping with the baby in another room not having sex with her husband) giving the therapist the opportunity to point out the conflict within in her culture isn't she supposed to be subservience to her husband, Or an American wife complains that her Japanese husband is cheap and cannot accept living being materialistic? Only to point out that Japan is a hub of materialism. Objects, in fact, often become the replacement for human contact.

\section{Responses from Mediators}

\section{The Western Couple}

I have great compassion for the trauma you experienced in your marriage and how you were the victim of abuse, how you were devalued for being a women, how you were shamed for having needs, these are issues you need to deal with in your therapy (which we recommend). Here we are only interested in division of property and what is best for the family and children!

\section{Middle Eastern/Asian Couples and Other Cultures: Common Complaints [5, 6]}

- Spouse needs to be more communicative

- Spouse wants more respect to be more loyal to wife than boss or country 
- Husband is more loyal to mother/big brother than wife

- Husband treats wife like a possession

- Spouse shows little emotion and expression of feelings

- Wife nurse baby until five years old (neglect of husband)

- Spouse is too controlling or too submissive

- Husband does not spend enough time with wife and children

\section{Conclusion}

Judges, attorneys, mediators, and other court officials need to be more aware of various personality disorders and their defenses to allow the true personalities of the couple involved in divorces or child-custody cases to be revealed. A well-trained judge or mediator can see right through the lies, manipulation, and false claims made by those who under the guise of caring can act out the most heinous revenge against a spouse in family court. The focus is more on negotiation and solution than on the couple's emotions but more on awareness of shame/blame/attack and revenge. The challenges cross0cultural couples bring to the court system. This article also brings to the awareness these couples bring to the court system. The court should order further sanctions for those who file unnecessary claims and escalate court cost and sabotages for the sole purpose of depleting their partner financially and emotionally. The courts have the power and the authority in a most constructive way to bring finality to long on-going battles.

\section{References}

[1] Lachkar, J. (1992). The narcissistic/borderline couple: A psychoanalytic perspective to marital conflict: New York: Bruner/Mazel.

[2] Eddy, W. (2016). High conflict personality in legal disputes. Unhooked Books, Scottsdale, Arizona.

[3] Lachkar. J. (2008). The V-spot: Healing the "V”ulnerable spot from emotional abuse. New York: Jason Aronson.

[4] Lachkar, J. (2013). The Disappearing Male. New York: Taylor and Francis.

[5] Lachkar, J. (2014). How to talk to a narcissist. New York: Taylor and Francis.

[6] Lachkar, J. (2014). How to talk to a borderline. New York: Taylor \& Francis.

[7] Lachkar, J. (2016). Courts beware of the borderline. September-October. Courts beware of the borderline personality: Implications for mediation, San Diego, CA. Association for Family Therapists.

[8] Lachkar, J. (2022). How to talk to an OCD. (in Progress)

[9] Lachkar J. (1998). The many faces of abuse: Treating the emotional abuse of high-functioning women. Northvale. NJ: Jason Aronson.

[10] Lachkar, J. (1998). Aggression and cruelty in cross-cultural couples. Paper presented at the Psychohistory Congress. Paris.

[11] Lachkar, J. (2004). The narcissistic/borderline couple: New approaches to marital therapy. New York: Taylor and Francis.

[12] Lachkar, J. (2008). Psychopathology of terrorism. Paper presented at Rand Corporation. $3^{\text {rd }}$ Annual Conference: Terrorism and Global Security. May 8-10, Santa Monica, CA.

[13] Lachkar, J. (2013). The disappearing male. New York: Taylor and Francis.

[14] Winnicott, D. W. (1940). The maturational process and the facilitating environment. New York: International Universities Press.

[15] Lachkar, J. (2016. September-October). Courts beware of the borderline personality: Implications for mediation, San Diego, CA. Association for Family Therapists.

[16] Berton, P. (1975). November. Understanding Japanese negotiating behavior. ISOP Intercom (Los Angeles: UCLA), $18(2), 1-8$.

[17] Lachkar, J. (2014). Common complaints in couple therapy. New York: Taylor \& Francis.

[18] Lachkar, J. (2014). How to talk to a narcissist, $2^{\text {nd }}$ Edition. New York: Taylor \& Francis.

[19] Lachkar, J. (2022). How to talk to an obsessive-compulsive. E-Books. International Psychotherapy Institute.

[20] Lachkar, J. (2018). New approaches to marital conflict: The dance, the bond the drama. E-Books. International Psychotherapy Institute. Jason Aronson Publisher, New York.

[21] Linehan, M. M. (1993). Cognitive behavioral treatment of borderline personality disorder. New York and London: The Guil- 
ford Press.

[22] Mahari, A. J. (2009). The borderline dance and the non-borderlines’ dilemma: www.aspergeradults.ca.

[23] Fairbairn, W. R. D. (1940). Schizoid factors in the personality. In Psychoanalytic studies of the personality (pp. 3-277). London: Routledge \& Keegan.

[24] Freud, S. (1914). On narcissism: An introduction. In J. Strachey (Ed. \& Trans.). The complete works of Sigmund Freud (standard ed., vol. 14, pp. 69-102). London: Hogarth Press.

[25] Klein, M. (1975). Envy and gratitude and other works. In R. E. Money-Kryle (Ed.). The writings of Melanie Klein, Vol. 1-1921-1945 (pp, 306-343). New York: Free Press. (Original work published 1937).

[26] Kohut, H. (1971). The analysis of the self. New York: International Universities Press.

[27] Kernberg, O. (1995). Love relations. Normality and pathology. New Haven, CT: New Haven Press. 